Como se vive se muere: familia, redes sociales y muerte infantil. Bronfman, Mario. Cuernavaca, UNAM - Centro Regional de Investigaciones Multidisciplinarias, 2000, $387 \mathrm{pp}$.

\section{Helena Oliveira}

Departamento de Saúde Coletiva,

Universidade Iguaçu

A mortalidade infantil é um tema de presença constante na agenda da saúde pública e seu valor como indicador de saúde vem declinando progressivamente ao longo das últimas décadas, em todo o mundo. No entanto, a persistência de algumas destas "mortes evitáveis" continua motivando investigações. Fatores como idade, paridade, escolaridade materna, renda e saneamento, entre outros, têm sido responsabilizados na determinação desses óbitos em estudos epidemiológicos que incluem variáveis sociais. Embora essa relevância dada ao social represente um avanço para a ciência epidemiológica tradicional, nem sempre este tem sido considerado em toda a sua dimensão. Essa lacuna aparece, por exemplo, quando se busca responder à questão formulada por Bronfman, e que deu origem ao livro que motiva esta resenha: por que, nas mesmas condições econômicas e sociais, algumas famílias conseguem garantir a sobrevivência de suas crianças, e outras não? O que haveria, neste mesmo social, acarretado esta diferença?

Renomado sociólogo argentino, Bronfman vem desenvolvendo importantes pesquisas, elegendo como um dos temas prioritários o papel das redes sociais e da família na saúde. Ao observar que, em 1982, na Cidade do México, 50\% dos óbitos infantis ocorriam em apenas $5 \%$ das famílias, e que estas mesmas famílias apresentavam mais de um óbito infantil, o autor se viu instigado a iniciar uma investigação. Para tal, partiu do pressuposto de que os fatores sociais não eram variáveis a mais, compondo um somatório de riscos, porém estavam inscritos no biológico, modificando-o de forma íntima, complexa e singular. Formulou então a hipótese de que a estrutura e a dinâmica de cada família seriam os responsáveis por este diferencial de riscos para a mortalidade infantil.

A Teoria Geral dos Sistemas - com sua concepção de "sistemas" e "redes" - e suas vertentes sociológica e psicológica - com as noções de "redes sociais", "estrutura" e "dinâmica familiar" - serviu de base teórica para o percurso construído.

Para compreender seu objeto, assim delineado, o autor realizou entrevistas domiciliares com 72 famílias, divididas em três grupos de mesmo tamanho, pareadas segundo variáveis de moradia, paridade e idade materna. O grupo "caso" foi constituído por famílias com mais de um filho morto; dois grupos "controle" foram compostos por famílias com um e nenhum filho morto, respectivamente. Para as entrevistas foram utilizados roteiros abertos, contendo dados relativos a aspectos socioeconômicos e culturais da saúde, alimentação, hábitos de educação de filhos, condições de gestação, parto e puerpério, estrutura e dinâmica da família, além de dados objetivos que permitissem quantificações.
Para uma parte do material o autor recorreu à metodologia quantitativa de análise, com o objetivo de descrever de onde vinham as famílias entrevistadas, que preparo apresentavam, de que viviam, onde viviam e como sobreviviam - caracterizando suas condições de vida e contextualizando a interpretação dos dados registrados através dos roteiros abertos. Se, por um lado, fica claro para o leitor que a utilização de recursos estatísticos mais refinados poderia enriquecer, sobremaneira, esta análise, fica também explícito que a mesma se mostrou suficiente para os objetivos a que se propôs o autor. Ou seja, abrir caminhos para uma análise compreensiva e qualitativa da mortalidade infantil, na perspectiva da estrutura e dinâmica da família - e que é a mais original e importante contribuição desta obra.

A mesma é composta por oito capítulos. Os dois primeiros são dedicados à justificativa para a escolha do tema, à formulação da questão, ao desenho do estudo e à contextualização das famílias. Nos seis capítulos seguintes o autor apresenta a análise qualitativa, propriamente dita, das entrevistas, nas temáticas da família, das redes sociais, da educação das crianças, das enfermidades e acidentes infantis não-fatais, da utilização dos serviços de saúde e da antropologia das mortes infantis, respectivamente - sempre referidos a cada um dos três grupos de famílias estudadas.

O início de cada um deles caracteriza-se por uma sistemática e cuidadosa problematização do tema em questão, o que oferece ao leitor uma oportunidade ímpar de leitura e o acesso a numerosas referências bibliográficas. Além disso, contundentes depoimentos estruturam e fundamentam a análise - o que transforma a teoria utilizada em algo extremamente vivo e sensível.

O capítulo três, que trata da família, começa com a problematização dos conceitos já existentes sobre o assunto, seguida de um panorama das várias relações possíveis entre família e saúde. É neste capítulo que o autor faz a opção pela Teoria Geral dos Sistemas, e define família como um sistema, em contínua interação com outros sistemas. A organização, estrutura e dinâmica familiar - com sua flexibilidade e rigidez, ameaças e conflitos, permeabilidade e hierarquias - são aspectos a partir dos quais o autor propõe um modelo de análise do risco diferencial da mortalidade infantil, apresentando uma descrição clara, precisa e bem fundamentada de cada um deles.

A problematização e conceituação das "redes sociais" ocupam o autor no capítulo quatro. É também brilhante a revisão bibliográfica, crítica, que apresenta sobre o tema, na perspectiva das várias disciplinas das ciências sociais. A partir de uma ampla classificação que contempla a conectividade e a densidade dessas redes, são definidos critérios para agrupá-las em maior ou menor risco potencial para mortes infantis.

No capítulo cinco o autor retoma instigantes temas relativos à educação das crianças, não só no que diz respeito a seus aspectos históricos, culturais e psicológicos, como também sobre o reflexo dos conflitos familiares nesta atenção e cuidado.

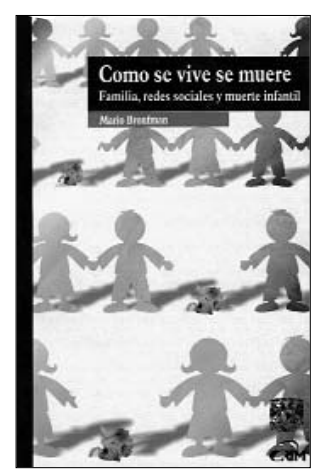


O capítulo seis discorre sobre a maneira como as famílias lidam com as enfermidades e os acidentes domésticos infantis não-fatais. A presença das redes sociais mostrou ser um aspecto de suma relevância, não só pelo apoio oferecido nas atividades do cotidiano, como também por viabilizar o acesso das famílias aos recursos assistenciais disponíveis na comunidade local. O autor é enfático ao afirmar que a capacidade familiar de construir redes de apoio, junto a algumas outras características da mesma, explicam, em grande medida, as mortes infantis. O capítulo sete explicita melhor a utilização e o acesso dessas famílias aos serviços de saúde.

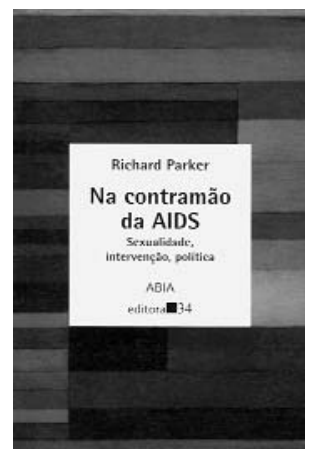

Na contramão da Aids: sexualidade, intervenção, política. Parker, Richard. Rio de Janeiro: ABIA-Editora 34, São Paulo-Rio de Janeiro, 2000, 59 pp.

\section{Murilo Peixoto da Mota}

Universidade Federal do Rio de Janeiro

Este é sem dúvida um livro provocativo, instigante e obrigatório para estudantes, pesquisadores, profissionais e público em geral que, direta ou indiretamente, sentem-se afetados pela pandemia do HIV/Aids.

$\mathrm{O}$ autor, conhecido entre nós por suas incansáveis contribuições nas reflexões sobre a sexualidade e discussões sobre o impacto da Aids na sociedade, explicita em Na contramão da Aids: sexualidade, intervenção, política um certo campo de forças heterogêneo, interdisciplinar, múltiplo, aspecto necessário para viabilizar a construção de estratégias mais eficazes na luta contra o a epidemia. Essa heterogeneidade contida nas idéias apresentadas no livro pode ser percebida até no formato, divido em três partes, com três ensaios cada uma, onde os temas sexualidade, intervenção e política se sobressaem do início ao fim sem "compartimentações cartesianas".

Richard Parker organizou uma coletânea de textos escritos ao longo da década de 1990, apresentados por ele em seminários internacionais, como contribuição na luta contra a disseminação de uma pandemia crescentemente atrelada às desigualdades "socio-sexuais" nesta virada de milênio.

Podemos salientar que a leitura de $\mathrm{Na}$ contramão da Aids: sexualidade, intervenção, política é necessária porque possibilita uma nova leitura da pandemia, na contramão do que vem sendo dito sobre ela. O livro contém uma escrita provocativa e direta, por isso mesmo está acessível a qualquer pessoa interessada no tema. Além disso, tem conteúdos denunciadores de tendências que marcaram os caminhos da Aids nesta última década, aspecto que o coloca como marcador histórico de um decênio de questões culturais, principalmente em torno da sexualidade e que estão muito mais visíveis agora. Talvez seja esse o grande legado desta coletânea de artigos: dar visibilidade, de maneira frontal e direta, aos caminhos trilhados pela Aids no mundo, demonstrando o quanto sua trajetória esteve atrelada aos mais pobres, discri-
E no último capítulo, continuando a criar uma relação íntima e firme entre a teoria e o material empírico, Bronfman finaliza com uma análise antropológica das mortes infantis. Privilegia os aspectos da dinâmica familiar e das redes sociais, para elucidar, uma vez mais, seu papel nos riscos e na experiência da morte em crianças pequenas.

Pela seriedade e inovação que apresenta, é leitura obrigatória para os que se propõem a alargar seu universo conceitual e metodológico a respeito de tão triste e, infelizmente, ainda atual tema - e o conseqüente alcance e eficácia de suas ações. minados, considerados "abaixo" nos estereótipos e hierarquias de gênero.

Veterano nas reflexões que lidam com o debate da epidemia no Brasil, Parker já influenciou gerações de pesquisadores e continua a influenciar a análise do panorama da pandemia desde seus primórdios, nos quatro cantos do mundo. Sua contribuição tem tomadas de posições peculiares, que articulam ciência política e antropologia para os estudos da sexualidade e para os amplos contextos nos quais se insere o HIV/Aids no mundo.

No campo antropológico, sua disciplina de origem, o conjunto de ensaios reunidos no livro nos dá a visibilidade necessária para compreendermos as amplas questões culturais contidas naquilo que o autor chamou de "violência estrutural", segundo a qual setores populacionais mais marginalizados convivem com os "riscos" e vulnerabilidades que influenciam na disseminação do HIV. Interessante, que é no campo político que Parker aparece como inspirador, pois nos dá uma reflexão fundamental para entendermos o atual panorama da disseminação do HIV e as políticas públicas destinadas ao seu combate. Nessa vertente, Na contramão da Aids: sexualidade, intervenção, política nos acena não só relativizando metodologias como possibilitando também ser uma via de mão dupla, pois dá visibilidade às contradições das estratégias governamentais, deixando um alerta para os que acreditam no "mito justificador" de que a pandemia está devidamente controlada. Politicamente o livro alerta para os cuidados que deveríamos ter ao analisarmos o contexto da disseminação do HIV e para o fato de que, utilizando suas palavras, "a epidemia prospera, apesar de ter mudado de espaço social”.

Na contramão da Aids: sexualidade, intervenção, política não deixa de ser mais um legado de Parker para a complexa análise sobre a pandemia. Seus argumentos nos dão uma abordagem de primeiríssima mão a respeito de um debate muito próprio da era da Aids: as muito novas reflexões sobre as metodologias de pesquisa social no campo da sexualidade no Brasil, principalmente para aqueles que não tiveram acesso aos ensaios destes artigos editados em inglês.

Na contramão das suposições naturalistas sobre cultura sexual, Parker tem sido pioneiro no debate 
que articula sexualidade e epidemia da Aids à brasileira, a partir de pressupostos que incluem um olhar crítico sobre as análises "bio-psiquico-sociais" no contexto de concepções construtivistas. Vale destacar que esta publicação também nos possibilita o reconhecimento de autores e uma ampla bibliografia, nem sempre traduzidos para o português, que têm trazido grandes contribuições metodológicas para os estudos da cultura sexual, transmissão do HIV e prevenção da Aids no mundo.

A análise da Aids no livro contribui com importantes reflexões que certamente se opõem a um discurso dominante, emergente e simplista, que enfatiza uma epidemia administrada, discurso muito propagado pela "indústria" que se criou em torno da Aids, alimentado por fantasiosos resultados estatísti-

Previdência social e mercado no Brasil: a presença empresarial na trajetória da política social brasileira. Delgado, Ignácio Godinho. LTr, São Paulo, 2001, 317 pp.

Ligia Bahia

Faculdade de Medicina, Núcleo de Estudos de Saúde Coletiva da Universidade Federal do Rio de Janeiro

A publicação de Previdência social e mercado no Brasil: a presença empresarial na trajetória da política social brasileira que resulta do trabalho de dissertação de doutorado de Ignácio Godinho Delgado é extremamente relevante e oportuna. Relevante porque examina as aparentes rupturas e descontinuidades dos padrões das políticas de proteção social no Brasil, através de um fio condutor que tece uma reflexão mais aprofundada sobre as identidades e mudanças da previdência social do desenvolvimentismo para o reforço à lógica do seguro privado, que a orienta mais recentemente. Oportuna porque, na atual conjuntura, este trabalho interessa de perto a leitores afetos ao tema sejam os pesquisadores sejam os que se preocupam com as transformações que ocorrem no país.

Trata-se de uma investigação rigorosa das coalizões de interesses entre trabalhadores, empresários e governo que delimitam as trajetórias das políticas de proteção social desde a criação da Previdência Social até os dias atuais. O enfoque escolhido pelo autor a análise do posicionamento dos empresários mais favorável a adoção das políticas sociais modernas ou daquelas de cunho assistencialista e da influência das classes empresariais na formulação e implementação das políticas previdenciárias - se faz acompanhar por um desenvolvimento teórico-conceitual à altura dos desafios da complexidade do objeto.

Ao remeter questões à economia e às ciências políticas, o autor sugere que os empresários preferem, de modo geral, evitar a contribuição patronal para a estruturação dos sistemas de proteção social. As condições de concorrência entre as empresas e as possibilidades de coalizões entre os atores funda- cos e justificativas que objetivam desresponsabilizar alguns pela realidade da continuidade de dispersão do HIV.

Por fim, o livro oferece a possibilidade de se estabelecerem discussões críticas em torno das tradicionais tendências dominantes das pesquisas, intervenções e políticas com relação a prevenção do HIV. Trata-se de obra essencial para os que pretendem estar a par das discussões e dos encaminhamentos que vêm sendo feitos atualmente a respeito da Aids no mundo.

Não resta dúvida que mais este livro de Parker oferece caminhos fecundos para a construção de alternativas de luta contra a Aids associada às lutas por direitos sexuais, contra a discriminação e o preconceito nos seus amplos aspectos.

mentais marcam a geração das políticas sociais modernas: o pessoal do Estado; os trabalhadores assalariados e os grandes empresários moldam as trajetórias e a extensão dos sistemas de proteção social.

Sob as políticas de proteção da indústria nacional, os empresários aceitam com mais facilidade a universalização das políticas previdenciárias já que seus custos, mesmo quando financiados pelas empresas ao serem repassados para os consumidores pouco afetam a competitividade entre as empresas. Ao contrário, as economias abertas favorecem a opção pela instituição de sistemas mais residuais. Para que a instituição de sistemas universalistas prevaleça em economias abertas é preciso que, em regimes democráticos, a presença dos trabalhadores industriais se manifeste com identidade política própria e transforme os conflitos sociais em demandas convergentes ao Estado pela adoção de sistemas de bem-estar social.

Segundo Ignácio Godinho Delgado, a imposição da estrutura corporativa e de capitalização da Previdência Social no Brasil deriva da condução das políticas sociais por um regime autoritário apoiado numa coalizão constituída, fundamentalmente, pelos empresários e o Estado.

Os empresários se conformaram a criação da Previdência Social de perfil contencionista, na medida em que conseguiam a constituição de defesas paralelas para a indústria manifestas no seu financiamento através de tributos à coletividade nos marcos de uma economia em que se acentuava o fechamento do mercado interno, no sentido de se assegurar a expansão da economia doméstica (Delgado, I, 2001: 134).

Durante a transição do Estado Novo para uma ordem democrática e o regime militar, a economia brasileira manteve-se fechada frente ao mercado mundial. No regime populista a presença dos trabalhadores na cena política gerou uma coalizão entre técnicos do Ministério do Trabalho, os trabalhistas e a esquerda em torno das proposições da ampliação dos benefícios previdenciários. Nesse período, os empresários adotaram uma postura defensiva e passaram a denunciar os malefícios da elevação das alí-

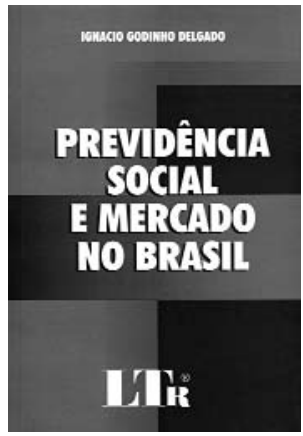


quotas de contribuição sobre o custo de vida e deplorar o distanciamento da previdência da lógica de capitalização e sua conversão a um regime de repartição simples.

O regime militar, consoante à missão de promover a integração nacional e atendendo aos interesses da coalização privatista que o sustentava, unificou os benefícios para os trabalhadores urbanos, estendeu a cobertura previdenciária aos trabalhadores rurais e empregados domésticos e ampliou a participação da iniciativa privada no sistema de proteção social. Até o final da década de 1970, o posicionamento dos empresários em relação à Previdência Social foi pouco expressivo. A redução do volume de contribuições à Previdência Social, decorrente da recessão econômica de 1981-1983, ensejou uma reedição das críticas dos empresários ao modelo de repartição simples e abandono dos critérios estritamente atuariais, como a concessão das aposentadorias por tempo de serviço e não por tempo de contribuição. É notável, como assinala o autor, que nesse momento nem a elevação das contribuições previdenciárias, num o quadro de recessão, nem a experiência chilena, em pleno curso neste mesmo período, tenham suscitado proposições empresariais direcionadas a reduzir o papel da previdência brasileira.

As pressões pela ampliação dos direitos sociais, ao longo da eleição e trabalhos do Congresso Constituinte, tampouco incitaram posicionamentos empresariais contrários aos princípios da seguridade social. Os empresários, cientes da possibilidade que dispunham de transferir os custos das políticas sociais, nos marcos de uma economia fechada, buscaram fundamentalmente impedir a aprovação daqueles dispositivos que podiam afetar o poder patronal dentro da empresa. Portanto, o que galvanizou as atenções das entidades empresariais foi a estabilidade no emprego.

Pouco tempo depois, o reconhecimento do caráter estrutural da crise da economia brasileira, o alinhamento do governo Collor às agências internacionais e o rompimento com os cânones do desenvolvimentismo inauguram a denominada "nova política econômica". As estratégias para flexibilizar o mercado de trabalho se acompanham pelas proposições de redução dos direitos sociais para atrair o capital internacional. $\mathrm{O}$ apoio de algumas entidades empresariais às mudanças na Previdência Social e legislação trabalhista direcionadas à redução do custo Brasil se concretiza na proposta da conversão da Previdência Social a uma "rede de proteção social ao cidadão" que restringiria a interferência governamental à arrecadação de recursos orçamentários destinados à distribuição de vouchers de serviços básicos a serem prestados competitivamente pelo setor privado e pelo setor público.

Todavia os empresários não lograram alcançar seus objetivos plenamente. Como se sabe, as mudanças introduzidas pela emenda constitucional no 20 e por sucessivas medidas administrativas não alteraram nem o modelo de financiamento e o caráter de repartição simples da Previdência Social nem o teto de seus benefícios. Para o autor, a resistência às ten- tativas de contra-reforma da Previdência Social tem sido bem conduzida. A defesa da Previdência Social pública conta com a participação de diversos atores, entre os quais o "pessoal do Estado". Isso não significa afirmar a derrota dos postulados neoliberais. As interrogações sobre a capacidade de os trabalhadores integrados à Previdência Social liderarem novos pactos que incluam os milhões de brasileiros que hoje estão à margem dos benefícios, bem como o incentivo governamental à proliferação de programas assistencialistas focalizados constituem imensos desafios à viabilidade da implementação da seguridade social.

Para a área de saúde este trabalho se reveste de particular importância pelo menos por duas ordens de razões. Em primeiro lugar nos relembra as estreitas relações entre as políticas de saúde e Previdência Social e convoca os estudiosos da saúde coletiva à reflexão e diálogo sobre os rumos do sistema de proteção social brasileiro. As demarchés empreendidas para a desmobilização da montagem de um sistema de seguridade social deslocaram a agenda da Reforma Sanitária para o âmbito estritamente setorial. Nos últimos anos produzimos estudos que aprofundam os debates e o conhecimento sobre problemas específicos da saúde. Mas nosso relativo afastamento das reflexões mais gerais nos deixa em dívida perante a literatura nacional sobre as políticas sociais.

Os mais rigorosos estudiosos do sistema de proteção social brasileiro, aos quais agora se soma Ignácio Godinho Delgado, enfatizam a privatização dos serviços de saúde para afirmar e exemplificar um processo de "americanização" das políticas sociais no Brasil. Sob variados enfoques essa literatura vem reiterando a existência de uma clivagem mais radical entre sistema de saúde público e privado do que a admitida pelos pesquisadores e profissionais de saúde. Tal dissonância estimula uma revisita às melhores tradições dos estudos da saúde coletiva sobre previdência e saúde e um intercâmbio mais sistemático entre os especialistas da saúde e os que se dedicam ao estudo dos sistemas de bem-estar social.

A segunda ordem de motivos que torna Previdência social e mercado no Brasil relevante para a área da saúde concerne à primorosa análise do autor sobre o ideário e as prescrições privatizantes dos empresários para a previdência e especialmente para os serviços de saúde. Após sua leitura, torna-se mais fácil entender a opção das empresas empregadoras, especialmente as das indústrias de grande porte, pelos planos privados de saúde em detrimento do apoio às políticas de saúde de corte universal.

Todas esses méritos tornam Previdência social e mercado no Brasil um orgulho para as instituições de ensino e pesquisa que passam a contar com mais um clássico da literatura sobre o tema. O impacto que este trabalho terá no âmbito dos pesquisadores e profissionais de saúde, certamente poderá ser atribuído, ao menos em parte, a inspiração de Luís Eugênio, irmão de Ignácio, nosso inesquecível companheiro sanitarista. A ele, e, portanto, à construção da reforma sanitária brasileira o livro é dedicado e honra. 
A crise na saúde pública e a utopia da saúde coletiva. Paim, J S \& Almeida Filho, N. Casa da Qualidade Editora, Salvador, 2000, 125pp.

Genesio Vicentin

Escola Nacional de Saúde Pública, Fundação Oswaldo Cruz

A obra tem um conteúdo vasto e inteiramente pertinente ao contexto da discussão sobre a saúde pública na virada do século XX. Esta consideração sobre a extensão temática da obra leva em conta que em seus seis capítulos são feitas abordagens que vão do plano filosófico, especificamente os paradigmas da ciência e da saúde pública, ao terreno prático da relação entre sistema formador de recursos humanos com o modelo sanitário dominante.

O capítulo um, denominado "Paradigma e crises”, presta-se às considerações sobre o conceito de paradigma em sentido estrito, como concepção de ciência, e em seu sentido amplo, como seria o caso de se admitir um paradigma da saúde pública. Neste caso, incorporando conceitos, vem tendo utilização múltipla e variada que pode confundir a própria concepção de paradigma. Por todos esses aspectos, este capítulo convida para uma nova leitura da obra de Kuhn (1975) e seu conceito de paradigma. Este, embora seja tomado como um referencial pelos autores, parece não corresponder mais às variadas formas como tem sido empregado.

No capitulo dois, os autores buscam uma definição de seu próprio referencial teórico valendo-se dos conceitos de "paradigma" e "campo científico". Também analisam a recente evolução dos movimentos e conceitos de saúde, nos planos público e coletivo, até o atual conceito de promoção da saúde. As aspas, dos autores, parecem revelar uma postura pragmática, que é assumida posteriormente e pode ser verificada nitidamente nos capítulos cinco e seis, onde são propostas alternativas.

No capítulo três, assumem a perspectiva de examinar os principais elementos do discurso dos movimentos ideológicos dos campos social e institucional posteriores à Segunda Guerra Mundial. Tomamnos como um marco histórico do surgimento de um novo paradigma da saúde pública. A partir desse marco, o foco é dirigido principalmente para os movimentos institucionalizados nos organismos internacionais, onde as proposições mais recentes de superação da desfavorável condição sanitária têm sido formuladas sem sintonia com as concepções paradigmáticas mais avançadas da saúde.

O capítulo quatro desenvolve o conceito de saúde coletiva como "campo científico" e "âmbito de práticas". Corresponde, também, ao momento em que os autores apresentam sua vinculação à saúde coletiva, diferenciando-a da saúde pública e da medicina social e situando-a num marco conceitual capaz de articular a abrangência de todos os níveis do campo da saúde.

No capítulo cinco, ocorre a transição para a opção que os autores denominam de pragmatismo. Segundo os mesmos este capítulo é uma tentativa de sistematização do marco conceitual da saúde coleti- va, em construção na América Latina, desenvolvendo-o particularmente no terreno transdisciplinar.

Mantendo-se na mesma perspectiva, no capítulo seis discutem o modo como a transição paradigmática poderá ensejar a constituição de novos sujeitos na saúde coletiva.

Sua leitura suscita questões pertinentes ao conceito de paradigma científico e sua relação com o contexto histórico, seja no plano geral dessa relação, ou no particular do desenvolvimento socioeconômico e político internacional na última metade do século XX, quando, segundo os autores, se formulou novo paradigma da saúde pública. Por conseqüência, evidencia também a questão da crise paradigmática particular no campo da saúde e da formulação de um novo paradigma para este contexto, independente da ocorrência de transformação social que lhe ofereça sustentação política e ideológica. Dessa forma, torna-se pertinente, mesmo nesta resenha, algum nível de polêmica.

Em sua obra, Paim \& Almeida Filho referenciam-se no conceito de Kuhn e localizam a formação do paradigma científico dominante, em seu sentido estrito, nos princípios de Hobbes sobre o estado, de Locke e Adam Smith sobre o mercado e de Rousseau, sobre a comunidade (pp. 75-76).

Entretanto, este tema não é desenvolvido na obra, e em outra parte apontam o surgimento de um novo paradigma da saúde pública no pós-II Guerra Mundial, em associação com os movimentos ideológicos formados dentro do próprio campo da saúde. Resultando uma contradição não resolvida entre o caráter progressista desses movimentos ideológicos, com seu novo paradigma, e as condições do processo socioeconômico internacional. Esta poderia efetivamente ser a base da crise na saúde pública. Menos paradigmática e mais estratégica, estrutural, expressada na contradição de um processo socioeconômico de crescente deterioração das condições de vida, fruto do distanciamento entre países ricos e pobres e entre camadas ricas e pobres, dentro de um mesmo país.

Os autores não a negam, mas privilegiam o contexto paradigmático projetando-se, em decorrência dessa opção, duas lacunas que reclamam estudos mais direcionados. A primeira, constituída pela necessidade de uma discussão mais profunda sobre a formação do paradigma cientifico em relação com o modo de produção dominante. Tema este que não é bem desenvolvido por Kuhn, e que por conter um conceito marxista não pode abdicar da inclusão de suas abordagens correlatas. Isso provavelmente daria um novo livro, e é um desafio ao avanço dos debates sobre a crise na saúde pública.

Por outro lado, ao privilegiar a discussão sob a ótica paradigmática, e afirmar o surgimento do novo paradigma de superação da saúde pública, como saúde coletiva, surgem duas novas questões essenciais. A primeira é a dos momentos históricos do surgimento do paradigma da saúde pública e o da sua superação. A segunda é a da própria superioridade do paradigma da saúde coletiva sobre o da saúde pública.

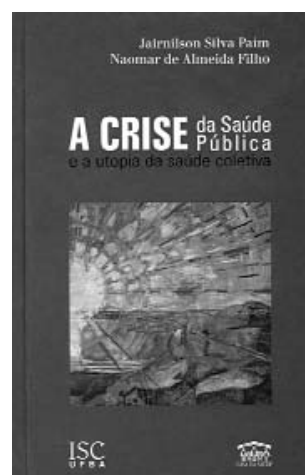


Sobre a primeira, a formação de um novo paradigma científico, no seu sentido estrito, compreende e sustenta-se sobre os elementos basilares de uma dada formação social (estado, o modo de produção, a organização social e os seus elementos ideológicos). Portanto, qual a transformação social ocorrida nestes componentes essenciais da sociedade, na última metade do século XX, que propiciasse o surgimento desse novo paradigma da saúde coletiva? Teria este surgido dissociado de um novo paradigma da ciência, no seu sentido de concepção global do conhecimento científico e de sua produção?

Talvez os autores, por sua perspectiva pragmáti$\mathrm{ca}$, não tenham se proposto responder todas estas questões. Mas é evidente que elas saltam à vista quando se põe em debate a crise da saúde pública. Além disso, qual a diferença essencial entre o paradigma da saúde coletiva (proposto pelos autores) e o que se pode inferir da obra de John Snow, formulada e executada em meados do século passado? Naquela oportunidade, explicou o desenvolvimento histórico das epidemias de cólera no nível internacional e da epidemia de cólera de Londres e a controlou mediante procedimentos políticos e administrativos, enfrentando grupos de interesses econômicos de então. Portanto, guardadas as diferenças atinentes ao momento histórico, inclusive do aspecto epidemiológico, pouco do que está presente no momento atual se diferencia, em essência, daquilo que estava presente na Londres de 1850, quando se pode inferir que o paradigma da saúde pública ganhou contornos definidos, embora não explicitados como ciência. Abre-se, portanto, novo campo de aprofundamento da questão da crise da saúde pública: existe, efetivamente, uma superioridade histórica e conceitual do paradigma da saúde coletiva sobre o da saúde pública?
Em linhas gerais, pode-se afirmar que a saúde pode não ser pública, mas é um objeto sempre coletivo. À luz do conhecimento atual não há saúde individualizada. Mesmo a medicina, reduto máximo do enfoque singular, reconhece a conotação social da morbidade. Mas, esta pode não ser a questão central para o desenvolvimento de nova concepção paradigmática para a saúde pública, embora seguramente tenha sido para a definição do objeto epidemiológico e da epidemiologia.

Talvez, a questão essencial da definição do paradigma da saúde pública seja exatamente o fato dela ser pública. Portanto, tendo no centro a questão do estado, como foi para Snow. E a saúde coletiva, que resposta oferece para essa última questão num momento em que é exatamente a redução da presença estatal o móvel principal dos agravamentos das crises econômica, social e epidemiológica?

Como se vê, o livro traz embutido o caráter polêmico. Temas como a formação de um novo paradigma para a saúde, agora dita coletiva em vez de pública, a perspectiva pragmática de sua implementação - mesmo sob a égide das atuais relações socioeconômicas internacionais, a referência a autores ligados à teoria da complexidade sugerindo a idéia de sua vinculação ao novo paradigma e a ausência de Marx e dos marxistas formam um contexto onde é impossível abdicar à polêmica. Mas, não é outro o objetivo da publicação, como é formulado em sua apresentação. Por seu conteúdo temático, trazendo ao debate questões relevantes da atualidade para o campo da saúde, por seu estímulo à reflexão e à polêmica e pela possibilidade de contribuir para o avanço na solução dos problemas de saúde recomendo a leitura deste livro. 